Natalia Jofré Poblete. Ecofeminista decolonial, Antropóloga Social por la Universidad de Chile y diplomada en Estudios de género y Teoría Feminista de la Universidad Central. Actualmente sustenta un proyecto personal llamado LiberAxión (www.feminismoliberaxion.com), donde se hace difusión sobre Feminismos de Abya Yala enfocado en el bienestar individual y colectivo. Su trabajo como antropóloga ha sido principalmente en temas de género, sexualidades, identidad barrial y ha colaborado en proyectos de investigación comunitarios e interdisciplinarios.

Paola Margarita Chaparro-Medina. Doctora en Filosofía con acentuación en Estudios de la Cultura por la Universidad Autónoma de Nuevo León, México. Magíster en Sociología por la Universidad de Arte y Ciencias Sociales de Santiago de Chile. Profesora-Investigadora en la Facultad de Filosofía y Letras de la Universidad Autónoma de Chihuahua, México. Sus líneas de investigación son: Estudios de género y biopolítica; análisis del discurso de los procesos de subjetivación y las relaciones de poder.

Historial editorial Recepción: 8 de septiembre de 2020.

Revisión: 11 de octubre de 2020. Aceptación: 23 de noviembre de 2020. Publicación: 13 de diciembre de 2020. 


\title{
Políticas de la representación urbana en Chile: irrupciones y disrupciones colectivas para imaginar otras ciudades desde la desmonumentalización
}

Politics of urban representation in Chile: collective irruptions and disruptions to imagine other cities from the demonumentalization

Política de representação urbana no Chile: irrupções coletivas e rupturas para imaginar outras cidades a partir da desmonumentalização

\author{
Natalia Jofré Poblete \\ Paola Margarita Chaparro-Medina \\ Universidad de Chile/Universidad Autónoma de Chibuabua \\ pchaparro@uach.mx
}

\section{Resumen}

Durante la revuelta social en Chile (octubre de 2019), las ciudades del país se convirtieron en territorios en disputa. En ellas se desplegaron diversas acciones colectivas que tensionaron el espacio público; emergiendo así una densidad emocional que planteaba la resignificación del espacio urbano, a través de la interrupción del orden de la representación dispuesto en la lógica de los símbolos materializada en los monumentos.

La ciudad constantemente entabla un diálogo entre distintas temporalidades, exponiendo, por una parte, las pautas de la representación; y por otro lado, la posibilidad para abrir estos espacios como una materialidad que permite la confluencia de otras formas de reconocernos e imaginarnos a partir de la conformación de nuevas significaciones.

Este proceso expresa emociones e imaginarios que confluyen en una diversidad de significados que buscan, entre otras cosas, visibilizar que el espacio urbano representa una lógica de poder colonial, patriarcal y clasista, que permiten el mantenimiento de un modelo neoliberal. En esta narrativa, las ciudades se presentan como espacios posibles, donde se pone en entredicho el orden de la representación y donde las subjetividades intentan transformarlas con una mano en la memoria y la otra en el futuro.

Palabras clave: Ciudad, Monumentos, Colonialidad, Memoria, Desmonumentalización, Emociones. 


\section{Abstract}

During the social upheaval in Chile (October 2019), the country's cities became disputed territories. In them various collective actions were deployed that stressed the public space; thus emerging an emotional density that proposed the resignification of urban space, through the interruption of the order of representation arranged in the logic of symbols materialized in monuments.

The city constantly establishes a dialogue between different temporalities, exposing, on the one hand, the patterns of representation; and on the other hand, the possibility of opening these spaces as a materiality that allows the confluence of other ways of recognizing and imagining ourselves from the conformation of new meanings.

This process expresses emotions and imaginaries that converge in a diversity of meanings that seek, among other things, to make visible that the urban space represents a logic of colonial, patriarchal and class power, which allows the maintenance of a neoliberal model. In this narrative, cities are presented as possible spaces, where the order of representation is challenged and where subjectivities try to transform them with one hand in memory and the other in the future.

\section{Keywords: City, Monuments, Coloniality, Memory, Demonumen- talization, Emotions.}

\section{RESUMO}

Durante a convulsão social no Chile (outubro de 2019), as cidades do país tornaram-se territórios disputados. Neles foram implantadas várias ações coletivas que valorizaram o espaço público; Emergindo assim uma densidade emocional que propunha a ressignificação do espaço urbano, através da interrupção da ordem de representação disposta na lógica dos símbolos materializados nos monumentos.

A cidade estabelece constantemente um diálogo entre diferentes temporalidades, expondo, por um lado, os padrões de representação; e, por outro lado, a possibilidade de abrir esses espaços como uma materialidade que permite a confluência de outras formas de nos reconhecer e imaginar a partir da conformação de novos significados.

Esse processo expressa emoções e imaginários que convergem em uma diversidade de significados que buscam, entre outras coisas, tornar visível que o espaço urbano representa uma lógica de poder colonial, patriarcal e de classe, que permite a manutenção de um modelo neoliberal. Nessa narrativa, as cidades são apresentadas como espaços possíveis, onde a ordem de representação é desafiada e onde as subjetividades procuram transformá-las com uma mão na memória e a outra no futuro.

\section{Palavras-chave: Cidade, Monumentos, Colonialidade, Memória, Demonumentalização, Emoções.}




\section{IRRUPCIONES EN LA CIUDAD Y DISRUPCIÓN DE LOS SÍMBOLOS CONDENSADOS EN LOS MONUMENTOS HISTÓRICOS}

El malestar hizo su aparición en Chile, recorrió calles, plazas, ciudades. Las manifestaciones se llenaban de pancartas con una multiplicidad de discursos que podríamos sintetizar en una de ellas: "Son tantas las wea's, que no se ni qué poner". Más que solo un descontento con el gobierno en turno, o con el sistema neoliberal, o por las dificultades de acceso a una vida digna para una gran parte de la población; el malestar irrumpía con una mayor fuerza, con una invocación a genealogías más profundas, a las configuraciones de dispositivos narrativos que habían impuesto desde mucho tiempo atrás los basamentos culturales para el mantenimiento de las desigualdades sociales.

A finales del mes de octubre y en el mes de noviembre del 2019 pudimos percatarnos de que ese malestar tenía toda la intención de exponer lo insondable del mismo, una de las muestras de esto fue la intervención y destrucción de monumentos históricos.

El primer registro de esto se realizó el 29 de octubre en la Región de la Araucanía, en la ciudad de Temuco. La estatua de Pedro de Valdivia y de Dagoberto Godoy (el primer aviador chileno que sobrevoló los Andes), fueron decapitados. Los días continuaron con muestras de desimbolización similares en las ciudades de Cañete, Collipulli, Concepción, y de nueva cuenta en Temuco. Más adelante, la estatua de Cristóbal Colón fue derribada en la ciudad de Arica. Asimismo, en la plaza de La Serena, lo mismo sucedió con la estatua del español Francisco Aguirre. Esta última acción además fue seguida por un acto de resignificación de la figura, pues fue instalada Milanka, una mujer diaguita que tiene una profunda relevancia para la simbología diaguita (Huenchumil y Mundaca, 2019).

En el extremo sur del país, en la ciudad de Punta Arenas, la escultura de José Menéndez, a quien se le atribuye el genocidio y extinción de los Selk'nam, pero que por otro lado, es un personaje que desde el discurso oficial es elogiado en su región, fue destruido, decapitado y llevado a los pies de la estatua del Indio Patagón de la plaza Muñoz Gameros (Urrejola, 2019).

En términos generales, de acuerdo a un documento oficial del Ministerio de las Culturas, se registraron 669 monumentos nacionales intervenidos, de los que 421 presentaron alteraciones, 24 monumentos históricos presentaron daños graves como colapsos, retiros y/o quema. Este registro fue realizado entre el 2 y el 7 de enero del 2020. Los principales daños se concentraron en la Región Metropolitana, seguido por las regiones de Tarapacá, Valparaíso, Los Lagos y Magallanes (Ministerio de las Culturas, 2020). 
Los Monumentos Históricos Nacionales son considerados como la materialidad del discurso público sobre la monumentalidad de la historia nacional. De acuerdo a Márquez, Rozas y Arriagada (2014), por Monumento Histórico Nacional se entiende: "aquel objeto $\mathrm{u}$ artefacto edificado que interpela y representa la historia nacional, pero valiéndose a menudo de la memoria viva y de los sentidos de la percepción a través de su forma y emplazamiento. En el monumento, el recuerdo del pasado como memoria o historia se actualiza en el presente a través de su forma y su estética, ambos convocan una identificación afectiva con una comunidad pasada” (p.60). Tomando en consideración esta cita, está claro que al considerar los monumentos históricos como patrimonio nacional, lo que queda claro es la potencia que tienen los símbolos representados en los monumentos en el establecimiento de referentes, valores, emociones y afecciones que conforman la vida en común, y por tanto, la instauración de la Política. Es así que el patrimonio material condensa las narrativas sobre una comunidad, los valores que se pretenden enaltecer y que servirán como referente ordenador de un diagrama jerárquico para las generaciones futuras. En esos términos, es necesario apuntar que en las sociedades latinoamericanas, el ideario desde el cual se construyeron las ciudades es europeizante. Además, los referentes patrimoniales fueron realizados desde una dinámica social exclusivista, y por tanto, excluyente (Márquez, Rozas y Arriagada, 2014).

En el caso de la ciudad de Santiago, la mayoría de sus 147 monumentos no solamente fueron construidos en el periodo conmemorativo del centenario de la Independencia, sino que, lo más importante a destacar, y así comprender el peso de las declaratorias patrimoniales, es que la mayor cantidad de declaratorias sobre los monumentos históricos nacionales en la capital del país fueron realizados durante el periodo de la dictadura militar (Márquez, Rozas y Arriagada, 2014).

Lo sucedido durante el estallido social en Chile no se trata, entonces, de un atentado abrupto y sin sentido en contra de la conmemoración de las figuras históricas, cuyos símbolos se encuentran materializados en monumentos, a través de los cuales se demarca y organiza la cuadratura político-morfológica urbana; por el contrario, la tensión se coloca en el acto de intervenir, descolocar y fragmentar la materialidad conmemorativa de la historia nacional, para colocar la incertidumbre, el malestar y la presencia de la memoria, desde una experiencialidad que lo que anuncia es principalmente un malestar frente al orden instituido (Rufer, 2009). 


\section{INTERRUPCIÓN DEL ORDEN SOCIAL Y POLÍTICO: POSICIONA- MIENTO DE LAS DIFERENCIAS EN EL TERRENO DE DISPUTA}

Para dimensionar lo anterior en su radicalidad, es importante tener en cuenta lo siguiente: que la existencia del Estado tiene como fundamento el mantenimiento del orden en la sociedad y la seguridad en un territorio delimitado. Para efectuar lo anterior, establece un ámbito de dominio que tiene como resultado la vinculación entre sujetos sociales en relaciones asimétricas.

En síntesis, el Estado como organismo que ordena y regula las desigualdades, logra su realización a través de mecanismos que administran la distribución de los recursos económicos y político-administrativos; además, mediante el uso legítimo de la fuerza coercitiva; $y$, principalmente, mediante el mantenimiento de la hegemonía cultural. Este último elemento lo destacamos dado que, a partir del mismo se hace posible la "normalización" de las relaciones de dominación presentes entre la ciudadanía. La concepción de ésta en el proyecto del Estado moderno es uno de los ejemplos de la cristalización de las prácticas hegemónicas que se encargan de conformar significaciones, en este caso de configurar una entelequia, la ciudadanía, para hacer posible la disolución de las contradicciones socioculturales (O'Donnell, 2006).

Ahora bien, existe otro componente basal sobre el cual prevalece el sentido de la existencia del Estado, en términos territoriales y políticos, y ese, en el caso que nos compete, es la nación. La nación es la amalgama de complementariedades y solidaridades en la cual se diluyen las diferencias materiales, étnicas, sexuales y etarias para constituir un marco que sirve como referente y ámbito de sentido para una población que habita un territorio bajo el dominio y control del Estado (Largacha, 2009; Lifschitz y Arenas 2012).

En ese sentido, la nación se convierte en una colectividad superior que se sobrepone a los intereses particulares, de tal forma que, en el imaginario nacional, las problemáticas instaladas por las diferencias entre los sujetos y las problemáticas de dominación asociadas a las mismas, quedan invisibilizadas. Dicha invisibilización se efectúa mediante los postulados de cohesión nacionalistas que tienden a la par de la concepción de ciudadanía a erradicar dichas "imperfecciones" sociales y culturales para negar la diferencia y aglutinar a los sujetos políticos en una dirección determinada: hacia el horizonte de sentido propuesto por el Estado nacional (Baczko, 1999; O’Donnell, 2006; Largacha, 2009). 
Es así, que los mitos fundacionales de una nación, así como la puesta en vigor de los símbolos que demarcan y delimitan constantemente la narración de un "nosotros", activan y refuerzan la cohesión de la idea estatal de la unidad (Rufer, 2009). Esto actualiza los elementos que mantienen la estructura de dominación del Estado y se logra a partir de la condensación de la narrativa nacional en un elemento en el que se aglutina lo común y se disipan las diferencias propias de la lucha entre contrarios: la identidad.

A propósito de lo arriba expuesto, no debemos desatender un conflicto inherente a la conformación de identidades en los países latinoamericanos; dado que la conformación de nuestros Estados nacionales ha sido una emulación de las propuestas de Occidente. En ese sentido, la identidad bajo la concepción europea, no se sostiene tal cual en las realidades latinoamericanas (Brunner, 1998).

Más que considerar la identidad como una imposibilidad en nuestras latitudes, lo que reconocemos son las matrices de pensamiento, los imaginarios que nos constituyen; y, principalmente, las estructuras lógicas que subyacen a las formas de dominación presentes. En principio, la colonia, en su doble acepción, en tanto proceso histórico, lo que se ha de reconocer como colonialismo; y, la colonialidad, como la combinación entre significaciones, símbolos y discursos que se imponen como los saberes articuladores del proyecto de la modernidad, hemos de reconocer el gran significante conquista/colonia como el locus de enunciación de Occidente que prevalece como nuestro barramiento simbólico (Mignolo, 2007).

En virtud de lo anterior, Occidente posicionó en su imaginario una valoración de las sociedades américo-hispanas en tanto otredad. Las implicaciones de esta operación fueron no solamente la ocupación militar, sino principalmente la configuración de un territorio a ser dominado y explotado. Esto resulta fundamental para comprender aquello que Mignolo exponía con respecto a la lógica de la colonialidad, la cual considera que ha operado en al menos "cuatro dominios de la experiencia humana: 1) económico: apropiación de la tierra, explotación de la mano de obra y control de las finanzas; 2) político: control de la autoridad; 3) social: control del género y la sexualidad, y 4) epistémico y subjetivo/personal: control del conocimiento y la subjetividad" (Mignolo, 2007. p.36).

En ese sentido, el significante conquista/colonia sienta las bases, constituye el sustrato desde el cual se funda no sólo lo político en América Latina, sino que, además, desde éste se instala todo un régimen de producción de identidad y diferencia -de relación con lo Otro fundamentado en un elemento racial-, el cual está completa- 
mente atravesado por un factor de dominación. Por tanto, la explicación que la conquista/colonia realiza sobre sí misma, el relato que ella tiende a elaborar sobre su práctica, está dado por el posicionamiento de discursos que la justifican y valoran, esta operación se efectúa principalmente por medio de discursos que destacan el dominio bélico y cultural de Occidente.

El discurso historiográfico constituirá parte de una operación narrativa en la que la conquista es presentada como el hito civilizatorio y, por tanto, el colonialismo, como el proceso de instauración de un ordenamiento axiológico, una matriz de diferenciación étnico-racial propia del sistema de castas de la estructura colonial. Por tanto, de no entrar a tensar esto y elaborar una crítica radical sobre sus cimientos, se perpetúan los esquemas de subordinación sustentados en principios raciales, en donde el polo civilizatorio europeizante, moderno, patriarcal y blanco se mantendrá como el telos societal, dejando por fuera, o en posiciones subalternas, a la diversidad y multiplicidad de posibilidades de la vida cultural latinoamericana.

\section{Tensiones SOBRE El SIgNificAnte conQuista/colonia Y RESIGNIFACIONES DESDE LA “OTREDAD”}

Para eso están los monumentos para derribarlos cuando no representan nada.

Twit

Lo que se pone en tensión al intervenir, derribar, erradicar los monumentos que representan los artilugios de este poder, es la regulación pública del pasado. Se pone en evidencia la existencia de dispositivos de memoria pública que tienen por objeto la condensación material de una narrativa nacional, con altos grados de herencia colonial y significación patriarcal (Martín-Barbero, 2001). No es meramente una tensión sobre un referente histórico específico, no es contra un personaje en concreto, sino que lo que evidenciamos es la apertura a una discusión sobre los referentes que organizan el espacio público, que condensan los puntos neurálgicos de la ciudad como espacio de encuentro (Catelli, 2014).

La tensión sobre los monumentos en tanto referentes históricos se efectuó mediante intervenciones a los monumentos, desde pintura, inscripciones, rayones, grafitti, stencil, hasta su decapitación. Ese daño, o, mejor dicho, esa resignificación, posiciona no solamente un malestar colectivo, sino que también inscribe una temporalidad en el artefacto. 
En esos términos, irrumpir políticamente contra el patrimonio, establece no solamente una tensión en contra de un pasado para que éste no sea repetido, sino que, el acento es colocado en la posibilidad de un futuro en el que puedan ser instauradas otras formas de experiencia de la política, y, por tanto, otras pautas en las relaciones de poder (Jelin, 2014; Rufer, 2009).

Pareciera que está de más decir que lo anterior se trata de un problema de orden político, sin embargo, lo que buscamos a lo largo de este trabajo es ampliar ese espectro. Es decir, una vez que hemos dejado claro que los monumentos tienen una capacidad para producir significados sociales, pues, aunque en gran parte de nuestras cotidianidades parecieran estar invisibles, casi ausentes en nuestros recorridos urbanos; es importante destacar que es en la irrupción de los acontecimientos del estallido social lo que hace evidente la manera en que el Estado ha hecho uso para mantener un orden de la representación, y por tanto, el mantenimiento del orden político-social (Baczko, 1999).

Esa condensación historiográfica dispuesta en los monumentos, se nos presenta en estos actos como el campo de disputa entre lo hegemónico y lo subalterno. En ese sentido, los sectores excluidos en el reparto de las representaciones dispuestas por las narraciones historiográficas nacionales, que posicionan como sus actores histórico-políticos relevantes a los varones, hispanos, o bien, criollos, aristócratas, o bien, oligarcas, según el contexto histórico en el que se inscriban, efectúan en esa unificación en torno a una figura emblemática, la disolución de la otredad en oposición a sus atributos histórico-políticos. Esa disputa por lo simbólico, lejos de ser un mero arrebato de las masas inconformes, se convierten en maneras de ampliar el terreno político de la disputa, en el cual la apropiación del espacio urbano se convierte también en posibilidades para imaginar futuros desde sus reclamos en el presente (Rufer, 2009).

Los monumentos, en tanto símbolos que representan un orden social, cuentan una historia: esa que llaman "oficial”, y también esa que ha sido borrada. Porque los monumentos también hablan desde lo que callan. Las borraduras de la memoria impuesta por la moderni$\mathrm{dad} /$ colonialidad son narradas a través de estas estatuas grandes, duras y frías.

$\mathrm{El}$ orden monumental es un orden anquilosado, es un espacio vacío del presente de la presencia. Los monumentos representan a figuras patriarcales consideradas "héroes de la patria" por instaurar políticas crudas de violencia y erradicación de grupos humanos: los oligarcas, los militares, los genocidas (Huinca, 2019). Todos ellos hi- 
cieron de la fuerza su forma de legitimación, incluyendo el saqueo, la masacre, la posesión, la violencia.

La intervención de los monumentos puede ser leída como una "aiesthesis ${ }^{1}$ decolonial" (Vásquez, 2015), es decir, como una trasgresión del dominio del espacio como centro, donde existe un tiempo vacuo entre un pasado inerte y un futuro utópico. Gracias a esta trasgresión se posibilita la apertura de otro tipo de relación entre el tiempo y el espacio, "abre lo que ahora en la Universidad de la Tierra de Chiapas están llamando el ancho presente o lo que yo llamaría, no un tiempo lineal o circular, sino un tiempo relacional." (Vazquez, 2016: 81)

Quienes derrumban monumentos están añorando este tiempo relacional, apelan por una pluralidad espacial, donde la historia no puede ser contada solamente desde la vereda colonial. Derrumbamos para crear nuestras propias narrativas espaciales y temporales. La aiesthesis decolonial que propone Rolando Vásquez pasa por "convocar los tiempos que han sido silenciados, ignorados y que contienen otras posibilidades, que contienen otras formas de relacionarnos y ordenar la presencia, de relacionarnos al mundo, de habitar y nombrar nuestro mundo" (ibid.: 82).

Esta pluralidad temporo-espacial da cuenta de las experiencias vividas, de las memorias ancestrales, de las relaciones entre los mundos. "El escuchar los tiempos silenciados permite abrir otras formas de vivencias al mundo" (ibid.). La acción de derrocar monumentos como una expresión de aesthesis decolonial se opone a lo impuesto por la modernidad, donde el tiempo se sostiene desde lo lineal, estructurado, racionalizado, cuantificado y objetivizado.

Derrocar un monumento es abolir con un pasado que no se quiere, no se siente, con el cual no hay identificación ni representación. Es dar cuenta de las experiencias múltiples que han sido ignoradas y de las que se nos ha escindido colonialmente. Es recuperar la memoria, la historia no contada, cuestionar los cánones del oficialismo y la hegemonía urbana que habita en los espacios públicos.

En muchos centros urbanos de Chile, desde el 18 de Octubre, se encuentran las calles llenas de rayados, afiches con mensajes de "resistencia" y "dignidad", y dibujos que aluden a la revuelta social. En Plaza de la Dignidad, ex Plaza Baquedano, incluso se colocaron esculturas talladas que representan a los pueblos indígenas. Bajando las escaleras para acceder al metro (transporte público subterráneo) se creó un "jardín de la resistencia”, donde se plantaron diversas especies,

1 La palabra "aiesthesis" es griega y está íntimamente relacionada con la estética. Su significado no es unívoco, y apunta a la capacidad de sentir, a la comprensión a través de los sentidos, y/o al ejercicio de las sensaciones. 
acompañadas por un cartel con su nombre y el de las personas que han muerto producto de la revuelta social ("les caídos del estallido social”). $\mathrm{Al}$ presenciar de cerca estos mensajes, cómo se posiciona lo simbólico en el entramado de la urbe colonial, se vuelve imposible la ausencia de la emotividad. Probablemente nos conmovamos de una u otra forma. Todos estos ejemplos de expresiones de aesthesis decolonial evocan un móvil emocional.
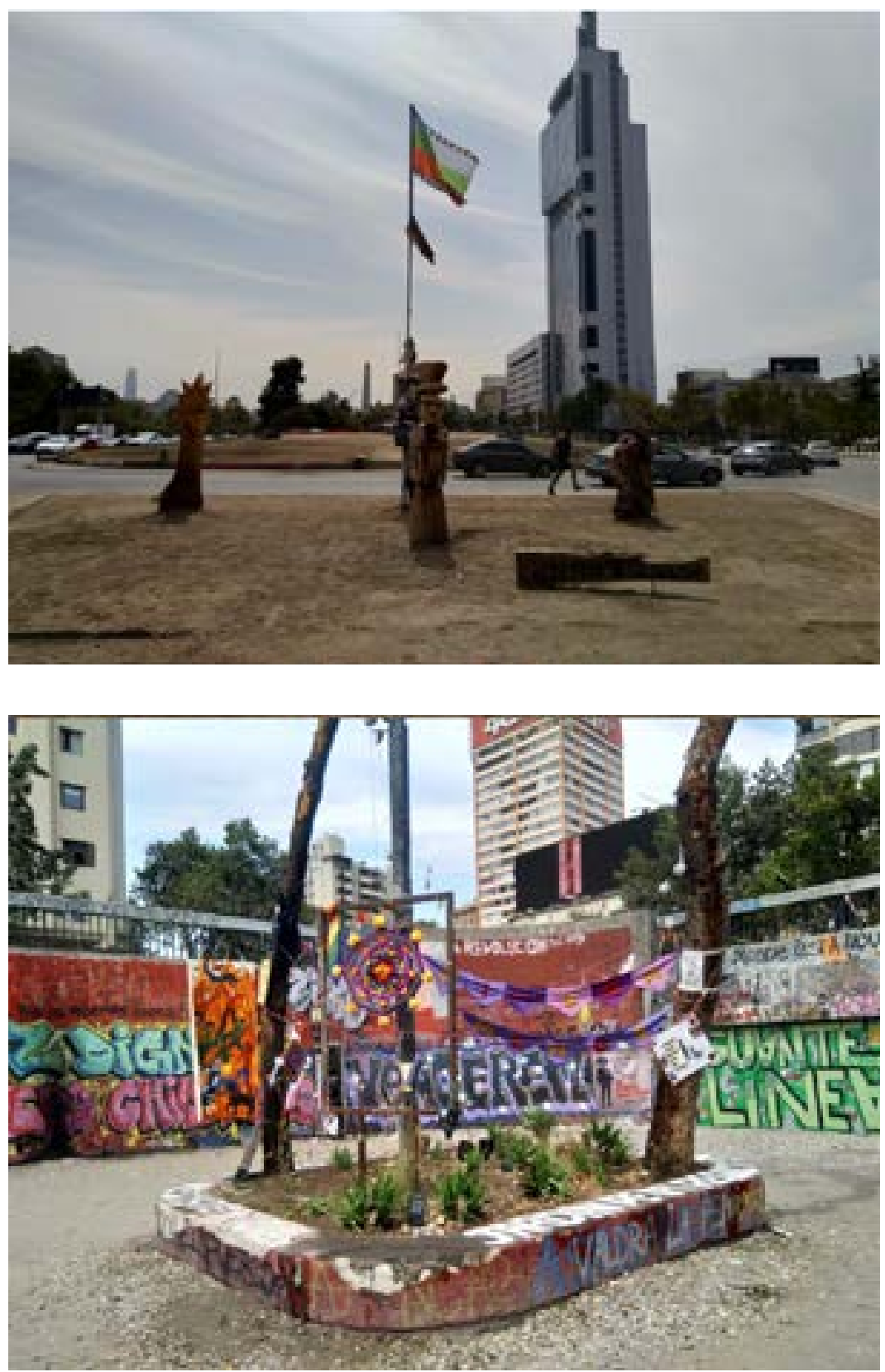


\title{
INTERVENCIÓN DE LOS MONUMENTOS Y EMOCIONES EN LA CIUDAD
}

\author{
Somos el río recuperando su cauce. \\ Consigna de lienzo
}

Dentro de las Ciencias Sociales, el foco de las últimas décadas ha ido construyéndose sobre las dimensiones no tangibles, como lo son las emociones, el cual en América Latina lleva alrededor de tres décadas (Lindón, 2007). El llamado "giro emocional", o subjetivista, de la teoría social nos lleva a preguntarnos por las emociones en toda orden de fenómeno sociocultural. La palabra "emoción" viene del latín "emovere", que alude a mover, o movimiento. Siguiendo a Sara Ahmed (2014) las emociones no se entienden como un constructo individual ni como parte de un modelo psicológico de interiorización, sino más bien como movilizadores desde un estado a otro, y al movernos nos vinculan con otros cuerpos que también están en movimiento. La proximidad de los cuerpos impulsa este movimiento.

En las movilizaciones sociales eso es lo que pasa: las emociones justamente "movilizan" a los sujetos. Ahmed entiende a la emoción en términos de circulación de afectos, donde se prioriza la importancia de los contactos e intercambios desde una economía material y simbólica, ya que “...los sentimientos no residen en los sujetos ni en los objetos, sino que son producidos como efectos de la circulación” (Ahmed 2014: 31). Las emociones nos mueven, y nos (con)mueven, debido a la proximidad con otros cuerpos y objetos.

A partir del estallido social se unifica la colectividad operando, por la cual las emociones se "pegan”. Las emociones, en esta lógica de circulación de afectos, se vuelven entidades colectivas que habitamos y nos habitan, dentro de un relato de permanente movimiento. Al igual que los cuerpos, no son unívocas, pues contienen múltiples dimensiones. A su vez, involucran cierta orientación hacia un objeto, por lo que son intencionales. Como resultado de una práctica social y cultural, condensan una lógica performativa, al dar como resultado diferentes tipos de orientaciones y acciones.

Las emociones también dependen de historias pasadas. En las multitudinarias marchas a partir de fines del 2019 se intervinieron los espacios públicos desde un pasado que gritaba. El derribamiento de los monumentos no es un sinsentido ni un vandalismo cualquiera; sino que es más bien un derribamiento simbólico, donde lo que se busca es derrocar el orden existente operante y la narrativa hegemónica relatada por el estado-nación chileno. "Las emociones nos muestran 
cómo se mantienen vivas las historias en los cuerpos, incluso cuando no se recuerdan de manera consciente; cómo las historias de colonialismo, esclavitud y violencia dan forma a las vidas y los mundos en el presente" (Ahmed, 2014: 304).

Los monumentos urbanos son una representación de este pasado: “(...) nos fuimos llenando de norte a sur de estatuas que remitían a los "constructores" de la patria (...) Una élite que (...) replica modos y discursos profundamente coloniales, con todo lo que eso conlleva: racismo, clasismo, expropiación territorial, eurocentrismo, y una larga lista de etcéteras”. (Allende, 2019: 1). Las estatuas, duras como este pasado anquilosado, condensan todo aquello de lo cual se está en contra. Contra ellas se dirigen la rabia y la indignación.

Las emociones muestran cómo el poder moldea las superficies mismas de los cuerpos y los mundos. Este móvil emocional está condicionado por una fuerte acumulación histórica de la rabia, como una respuesta a todo un sistema social que es tremendamente jerárquico, injusto y desigual. Se trata de una digna rabia, o de una rabia indignada. Una rabia que se indigna con los siglos de abusos. Una rabia que se agrupa y sólo así puede botar una estatua gigante.

La indignación acumulada históricamente en los cuerpos es la que les da la fuerza para estar en la calle, en la revuelta, interviniendo los espacios públicos, creando marcas nuevas en la ciudad. La indignación emerge como respuesta al dolor, dice que debe hacerse algo al respecto, otorgándonos la "energía" para reaccionar. Al final estos cuerpos responden no a una individualidad propia, sino a todo un colectivo que está tras de ellos: su familia, su comunidad, su pueblo. La indignidad es tan fuerte y grande en este país que se hacía llamar "el oasis" que todas las personas tenemos historias de dolor en nuestras genealogías verticales y horizontales. Alguien a quien el sistema de salud dejó morir, alguien que está endeudado de por vida por estudiar, alguien que no puede acceder a una vivienda propia, alguien que debe someterse a un sistema de trabajo explotador para costear la vida, alguien que su jubilación no le alcanza para una calidad de vida, alguien a quien le han contaminado su territorio... “ya no se puede más”. En palabras de Audre Lorde: "La ira es el dolor motivado por las distorsiones que nos afectan a todas, y su objetivo es el cambio" (Lorde, 1984: 144).

Derrocar los monumentos es gritar un gran “¡No!”. Pero éste no es un No que pone un punto final, sino que es un No de inicio. La negación como punto de partida "consiste en una grieta en el tejido de la dominación” (Holloway, 2006). Rayar y/o destruir los monumentos es una forma de crear estos intersticios en la representación simbólica del orden hegemónico. Cada intervención es una grieta en el tiempo y 
el espacio; a través de la cual emerge el tiempo presente, y se anuncia la creación de algo en el orden de lo posible (Hernández y Navarro, 2010). Y es que “...muchos de esos gestos son justamente una zona de purga, donde el relato del canon cultural suele ser mancillado, sublevado, contravenido y ofendido, como formas de cobrarle a ese canon las exclusiones históricas”. (Allende, 2019: 2).

Durante la revuelta social de Chile, los monumentos han sido intervenidos una y otra vez, para gritar continuamente muchos “ ¡No!”. La rabia, como resultado de marcas emocionales en los cuerpos, pone en diálogo el "yo" y el "nosotres", que se ven moldeados por el contacto con "les otres". Los monumentos cuentan cierta historia de este "nosotres", y la indignación con la que son intervenidos les viene a gritar “¡Basta!”. "Si la ira nos picotea la piel, nos hace estremecernos sudar y temblar, podría entonces conducirnos estremecidas hacia nuevas formas de ser; podría permitirnos habitar un tipo diferente de piel, aunque esa piel conserve las marcas y cicatrices causadas por aquello en contra de lo cual estamos" (Ahmed, 266).

\section{DE LA INDIGNACIÓN A LA ESPERANZA: IMAGINANDO OTRAS CIUDADES DESDE LAS POLÍTICAS DE LA REPRESENTACIÓN CO- LECTIVA}

La cueva.

La calle, cual Altamira, nos ofrece las paredes como lienzo en la cueva. Desde el anonimato, afloran los rayados espontáneos, que expresan de la forma más primaria, y visceral el mensaje. Este, lleno de una carga politica, hace que la ciudad nos grite. Nos enrostra asi el malestar generalizado

de una sociedad subyugada por años, que exige cambios y una forma de vida digna. Este recorrido nos invita a mirar, dialogar y por sobre todo a reflexionar en torno a estos textos, para reconocernos en los mensajes presentes en este imaginario, hechos en comunión y por una nueva colectividad de un pueblo que despertó.

Andrés Larraín

El pasado sigue abierto en el espacio urbano: los monumentos son cicatrices de la herida colonial. A partir de la revuelta social chilena “... se ha ido produciendo un enfrentamiento, a través de la destrucción y/o conservación de algunos monumentos de personajes relevantes de la historia nacional, que busca cambiar, borrar o resignificar, una(s) historia(s) de lo nacional y de la elaboración de un relato que incorpora a unos, invisibiliza a otros o que, derechamente, molesta a los con- 
trarios a estas figuras.” (Martínez, 2019: 39). Es en estas disrupciones de lo urbano donde emerge el espacio creativo, puesto en la escena a partir de la rabia indignada.

Esta rabia indignada se vuelve un motor creativo, una fuerza que impulsa a la transformación. “(...) cuando la ira se expresa y se traduce en obras al servicio de nuestra visión y de nuestro futuro, se convierte en un acto de clarificación liberador y fortalecedor (...)" (Lorde, 1984: 141). Entonces, "la indignación no se define simplemente en relación con un pasado, sino como una apertura hacia un futuro" (Ahmed, 2014: 265).

La indignación no se reduce simplemente a un antagonismo, a un "oponerse a", o "luchar contra", sino que continuamente moviliza hacia un mundo de posibilidades, "(...) como algo más creativo, algo que responde al mundo con alegría y cuidado, así como con atención a los detalles que sorprenden" (ibid., 271). Estar en contra de algo es también estar en favor de algo, aunque puede que aún no se tenga claro qué es ese algo al que se apela. La indignación es visionaria, movilizadora, y coloca un piso de incertidumbre frente al orden social existente.

Pero esta indignación necesita una traducción. La intervención de los monumentos y las calles se vuelven actos de traducción de la indignación, nombrando al dolor y planteando un mundo diferente. No obstante, la indignación sin esperanza se quedaría en agotamiento, un tiempo estático que no apuesta por "avanzar", sino que caería en lo iterable (op. cit). La esperanza implica que actuemos en el presente, pues en este momento ya estamos construyendo el futuro que anhelamos. Como dice el movimiento zapatista: "Es importante resistir, pero también es importante construir el mundo que queremos aquí y ahora".

La esperanza, entonces, convierte el presente en una disposición a tener confianza en el futuro. Moviliza hacia una relación diferente con el mundo, mantiene algo abierto, un sentido de lo posible. La esperanza acá no implica trascender el significado de los monumentos, anulándonos y pintándolos de blanco a modo de lienzo vacío, porque eso sería caer en las formas coloniales y neoliberales de la borradura. No se trata de dar vuelta la página simplemente y dejar atrás lo que ya pasó, sino, como dice bell hooks, "no olvidar el pasado, sino librarse de su dominio".

La fuerza transformadora decolonial es la posibilidad de aperturas relacionales, conectando nuestro presente con la memoria y la posibilidad. El tiempo relacional, o también, "reconstruir una relación con el tiempo" (Vásquez 2015: XX) implica que el espacio ya no 
gobierna el tiempo, ni que la urbanidad se sitúa por sobre la memoria, ni que los monumentos silencien lo no hegemónico. La esperanza nos permite los actos de protesta, porque sin ella podemos caer en un nihilismo, en un sinsentido del futuro (porque ya hemos visto que la historia se repite), o en un agotamiento profundo. Nos conecta con los afectos, con la generación de lazos, con el posicionamiento de los cuerpos desde un lugar creativo de resistencia. Finalmente, es "la esperanza de que las cosas pueden ser diferentes, y de que el mundo puede tomar diferentes formas" (278).

La frase "El pasado es una acumulación de desastres humanos, pero es también reservorio de conocimiento, razón y esperanza” (Gilly en Navarro y Hernández, 2010: 83) toma fuerza en este contexto. Es un aferramiento a este pasado lleno de injusticia (por la acumulación histórica de las políticas del despojo) y justicia (porque la memoria recuerda y sabe que hay otras realidades posibles desde la esperanza) para armarse y resistir. "El pasado se mantiene abierto en el presente, de manera tal que la historia del "yo soy" o "cómo llegué a ser" es una historia que también abre el futuro del sujeto" (Ahmed, 2014: 68).

La ciudad es también posibilidad. La ciudad pone en diálogo temporalidades: pasado-presente-futuro. Dentro de los estudios sobre lo urbano emerge la noción de imaginarios urbanos, que se refieren a una manera compartida de representar el espacio y el tiempo, siendo un producto de la interacción social entre las personas, construidos a partir de discursos, retóricas y prácticas sociales (Márquez, 2007). Aluden a matrices de sentidos situadas entre lo real y lo imaginado: lo que se desea, lo que no está, lo que se ha perdido, por lo que suponen un ánimo de visualizar lo invisible, una intención dirigida a un objeto ausente (Castoriadis, 1998)

Derrocar monumentos es insistir en un tiempo relacional, donde todo está emergiendo como presencia en cada presente continuo. Las ciudades están en constante transformación, creando y recreando imaginarios urbanos. Otro tipo de ciudad es otro tipo de sociedad. El tiempo relacional nos abre las puertas de la esperanza: "nos hace ver que es posible transformar el orden de la presencia a través de una relación activa con esa diversidad y sus alternativas que están en el tiempo y que no siempre están siendo actualizadas, sino que más bien han sido suprimidas por el orden de la modernidad/colonialidad" (Vazquez, 2016: 82). Es por esto que “(...) los imaginarios deben poder hablar de estas ciudades ideales que no son, sino una crítica al orden social" (Márquez, 2007: 87).

Dicha intervención es un grito de lo "no moderno/colonial" ante aquello que lo sepultó, sin lograrlo del todo. Los monumentos, en 
tanto condensación de símbolos, son parte de los imaginarios urbanos hegemónicos, los cuales configuran las sociedades al impulsar ciertas prácticas espaciales y dejando fuera otras ya que "al existir políticas de la memoria dominantes que se plasman en el espacio público, visibilizan los malestares subterráneos al mismo tiempo que niegan esas otras memorias" (Quezada y Alvarado, 2020: 3). El acto de intervenir un monumento es parte de los imaginarios urbanos de resistencia, "aquellos que propugnan por una ciudad y una vida urbana distintas de las que inducen los imaginarios dominantes" (Lindón y Hiernaux, 2008: 9).

Los imaginarios urbanos hablan del tránsito entre la memoria y la imaginación: pueden alimentarse de la memoria colectiva para producir una construcción fantasiosa, pero no por esto deja de orientar la acción social (Lindón, 2007). De hecho, en Chile no sólo se han intervenido monumentos, sino que también se han cambiado nombres de espacios públicos: La clásica Plaza Italia, lugar "de batalla" social por ser el ícono de encuentro de las manifestaciones de la capital, hoy en día es llamada Plaza de la Dignidad; en Valparaíso la clásica Aníbal Pinto actualmente es nombrada Plaza de la Resistencia; Avenida Francisco de Aguirre en La Serena fue cambiada por Avenida Diaguita (nombre de un pueblo indígena de la zona).

No es casual tampoco que el General Baquedano de la actual Plaza de la Dignidad, en Santiago, se haya vuelto a pintar una y otra vez, porque las autoridades de turno necesitan "blanquear la memoria" como una forma de "restituir el orden", orden que es simbólico, político, económico. Es una borradura, un blanqueamiento reaccionario, una tachadura, donde se niega la otredad de la hegemonía blanca que sólo acepta al "otro" cuando no lo hiere, mancha, critica, y cuando quiere ser parte de la comunidad (Quezada y Alvarado, 2020). Finalmente, "(...) la construcción de imaginarios, de principios de identificación y diferenciación se vuelven entonces ejercicios peligrosos" (Márquez, 2007:87).

Si la ciudad, entonces, se configura como este campo de disputa permanente, donde se juegan las lógicas de representación y se combinan lógicas de dominación y resistencia, vale entonces hacerse la pregunta sobre qué es lo que queremos entonces poner allí donde se bota una estatua, se raya un nombre, o se pinta un monumento, ¿qué pasado es el que vamos a poner en valor? "La memoria, con ello, se trasforma en un campo de disputa, en donde lo político y lo cotidiano se funden para tramar narrativas que fundamentan la praxis de los procesos actuales. Aquí yace la posibilidad de la desmonumentalización." (Quezada y Alvarado, 2020: 3). El pasado es el lugar de dónde 
venimos: un legado colonial que ya no queremos, pero que también contiene las claves a partir de las cuales nos hemos constituido, por tanto, su mantenimiento hace posible ampliar las perspectivas en torno a lo que somos.

\section{REFERENCIAS}

Ahmed, S. (2014). "La política cultural de las emociones". Centro de investigaciones y estudios de género, Universidad Nacional Autónoma de México.

Allende, M. (12 de noviembre del 2019). La parte por el todo: monumentos y gestos anticoloniales. Revista Palabra Pública. Recuperado de: https://palabrapublica.uchile.cl/2019/11/12/1a-parte-por-el-todo-monumentos-y-gestos-anticoloniales/

Auge, M. (2003). El tiempo en ruinas. Barcelona, España: Editorial Gedisa.

Bacz ко, B. (1999). Los imaginarios sociales. Memorias y esperanzas colectivas. Ediciones Nueva Visión.

Choay, F. (1993, November). Alegoría del Patrimonio. Arquitectura Viva, (33), 15-21.

-. (2009). El reino de lo urbano y la muerte de la ciudad. Andamios, 6(12), 157-187.

Catelli, L. (2014). Dispositivos de memoria y repertorios de lo sensible en la Serie 1989- 2000 de Luis González Palma. En Luis González Palma. Madrid: La Fábrica.

Huenchumil, P. y C. Mundaca (2019). “Derribar símbolos coloniales: Un nuevo acto político que se suma en las protestas en Chile”. En Interferencia. Nota publicada el 20 de noviembre de 2019.

Holloway, J. En Una charla de John Holloway: ¿Qué es la Revolución? Cooperativa lavaca. Recuperado de: https://www.lavaca.org/notas/ una-charla-de-john-holloway-\%C2\%BFque-es-la-revolucion/

Huinca, H. (15 de noviembre del 2019). El derribo de estatuas en las plazas de Chile y Wallmapu. La des-monumentalización de los iconos de la memoria histórica colonial. Comunidad de Historia Mapuche. Recuperado de: https://www.comunidadhistoriamapuche.cl/el-derribo-de-estatuas-en-las-plazas-de-chile-y-wallmapu-la-des-monumentalizacion-de-los-iconos-de-la-memoria-historica-colonial/

Gutiérrez, V. (3 de noviembre del 2019) “Estatuas, memoria y patrimonio”. Diario Universidad de Chile. Recuperado de: https://radio.uchile. cl/2019/11/03/estatuas-memoria-y-patrimonio/ 


\section{Políticas de la Representación urbana en Chile}

Jelin, E. (2014). “Memoria y democracia. Una relación incierta”. En Revista Mexicana de Ciencias Políticas y Sociales. Vol. 59. No. 221.

Largacha, C. (2009). "Identidad y memoria: la construcción de nación en América Latina”. En Comunicación, cultura y política. Revista de Ciencias Sociales. Vol. 1. No. 2: julio-diciembre 2019.

Lefebvre, H. (1974). La producción del espacio. Papers. Revista de Sociología, 3, 219-229. https://doi.org/10.5565/rev/papers/v3n0.880

Lifschitz, J. y S. Arenas (2012). “Memoria política y artefactos culturales”. En Revista estudios políticos-Universidad de Antioquia. Vol. 40 No. 1. Enero-junio de 2012: pp. 98-119

Lindón, A. (2007). La ciudad y la vida urbana a través de los imaginarios urbanos. Revista eure (Vol. XXXIII, No 99), Santiago de Chile, agosto de 2007: pp. 7-16. Disponible en: https://scielo.conicyt.cl/pdf/eure/ v33n99/art02.pdf

Lindón, A., \& Hiernaux, D. (2008). Los imaginarios urbanos de la dominación y la resistencia. Iztapalapa, Revista de Ciencias Sociales y Humanidades, (64-65), 7-14. Disponible en: https://www.redalyc. org/articulo.oa?id=393/39348722001

Lorde, A. (1984): "Usos de la ira: las mujeres responden al racismo". En La hermana, la extranjera. Artículos y conferencias.

Low, S (2006). "Transformaciones del espacio público en la ciudad latinoamericana: cambios espaciales y prácticas sociales”. Bifurcaciones.

—. (2009). "Cerrando y reabriendo espacio público en la ciudad latinoamericana”. Cuadernos de Antropología Social, 30, 17-38.

Martínez. J.L. (2019). Entre estatuas y memorias. Rompiendo una(s) historia(s) de lo nacional. Chile despertó. En Lecturas desde la Historia del estallido social de octubre. Universidad de Chile.

Márquez, F. (2007). Imaginarios urbanos en el Gran Santiago: huellas de una metamorfosis. EURE (Santiago), 33(99), 79-88. Disponible en: https://dx.doi.org/10.4067/S0250-71612007000200007

Márquez, F. Rozas, V. y R. Arriagada (2014). El lugar del patrimonio dominante. En ARQ Santiago. No. 88. Págs. 56-65.

Navarro, M. y Hernández, Oliver (2010). Antagonismo social de las luchas socioambientales en México: Cuerpo, emociones y subjetividad como terreno de lucha contra la afectación. Revista Latinoamericana de Estudios sobre Cuerpos, Emociones y Sociedad. Vol. 2(4),77-92. Disponible en: https://www.redalyc.org/articulo. oa?id=2732/273219411008

Quezada, I. y Alvarado, C. (2020). Repertorios anticoloniales en Plaza Dignidad: desmonumentalización y resignificación del espacio urbano en la Revuelta. Santiago de Chile, 2019. Aletheia, 10 (20), e049. Disponible en: https://doi.org/10.24215/18533701e049 
Martín-Barbero, J (2001). El futuro que habita la memoria. Departamento de Estudios Sociales, ITESO.

RufEr, M (2009). La nación en escenas. Memoria pública y usos del pasado en contextos poscoloniales. El Colegio de México.

Urrejola, J (2019). "Chile: destrucción de monumentos como protesta contra la historia oficial”. Publicado en https://p.dw.com/p/3Sq81. Nota publicada el 11 de noviembre de 2019.

VÁzquez. R, y Barrera. M (2016). Aesthesis decolonial y los tiempos relacionales. Entrevista a Rolando Vázquez. Calle14: revista de investigación en el campo del arte, 11(18), 76-93. Disponible en: https:// www.redalyc.org/articulo.oa?id=2790/279047494001 